\title{
Book Review: Models for Interdisciplinary Mobile Learning - Delivering Information to Students
}

\author{
Ali Simsek \\ Anadolu University, Turkey
}

\begin{abstract}
Introduction
The book is edited by Andrew Kitchenham from the University of Northern British Columbia (Canada) and published in 2011 by Information Science Reference (Hersey, PA), an imprint of IGI Global. The book (ISBN: 978-1-60960-511-7) has a total of 325+xxviii pages. It may be easily purchased through Internet or main bookstores of the world carrying academic titles.
\end{abstract}

The book has three sections including a total of 15 chapters. The first section has 5 chapters, the second has 6 chapters, and the third section has 4 chapters. A total of 33 authors have contributed to the chapters. The authors are selected from 7 countries; they are mainly from Canada, United Kingdom, United States, France, China, Malaysia, and Australia. The chapters are also reviewed by 34 reviewers representing the same countries, with the only exception of New Zealand.

Mobile learning, or m-learning, as the mobilization of e-learning can take place anytime and in any environment using state-of-the-art technologies that fit in the palm of the hand or can be carried from one place to another due to mobility needs. Models for Interdisciplinary Mobile Learning: Delivering Information to Students examines m-learning applications in various countries and sectors as individuals, groups, and institutions embrace mobile systems. The book expands on the current theories, applications, and outcomes of m-learning. It also explores how various types of e-learning practices have quickly transformed into mobile systems.

The book covers topics such as contemporary mobile technologies, evaluation of m-learning practices in the areas of education, business and medicine, augmented reality in mobile learning systems, m-learning through SMS text, capabilities of mobile technologies for distance education, generic principles and pedagogies for mobile learning, situation-based and activitybased m-learning strategies, standardized design with inherent flexibility for effective and efficient mobile learning, student perceptions about m-learning, mobile learning with the Net Generation, uses of wireless handheld devices for m-learning, the use of mobile technologies in foreign language classroom, and learner generated content in m-learning applications.

\section{Sections and Chapters}

The sections and the corresponding chapters in the book deal with a number of important issues in terms of $\mathrm{m}$-learning. The chapters have a balance among themselves contributing the comprehensiveness of the book. Their contents can be summarized as follows: 
The first section focuses on the theoretical aspects of mobile learning. This section contains five chapters dealing particularly with theories, philosophies, perspectives, and arguments about mobile learning.

Chapter 1 presents a review of scholarly work on mobile learning in the areas of education, business, and medicine. Three kinds of mobile devices are examined within the three subcategories of m-learning: the mobile phone or smartphone, the iPod, and the PDA. A total of 40 articles reporting about m-learning projects around the world are reviewed by following a mixed method design. It is understood from this comprehensive review that m-learning is used for extending learning opportunities in many parts of the world, mostly in developed countries of the North America, Western Europe, Far East Asia, and Oceania.

Chapter 2 presents generic principles and pedagogies for m-learning based on innovative research of the authors producing a five-part model. The chapter explains how the model was developed to create a strong research model that can be useful for others interested in $\mathrm{m}$ learning. Following a step-by-step approach, the chapter describes how reliable pedagogical principles were formed, tested, and revised. The chapter also illustrates how each stage of the model may be performed or how the overall process may be incorporated in a variety of educational settings.

Chapter 3 discusses the appropriate uses of mobile technologies and social media tools for college students. The authors ask an interesting question: "Do They Want Us in Their World?" After elaborating on the potential of mobile technologies for educators to transmit courserelevant information to students who generally perceive them as "fun" and "social", they conclude that students prefer to get their academic information through "official" channels such as e-mail and course management systems.

Chapter 4 describes a sample course design model, which has a standardized format with inherent flexibility, for effective and efficient mobile learning. The author discusses that the design of any e-learning environment, both blended and fully mobile, requires specific attention to self-regulated learning, cognitive load, and learner characteristics. The chapter ends with suggestions for future conversations and research.

Chapter 5 focuses on pervasive learning at the workplace. The authors highlight two popular but complementary strategies to fulfill seamless learning across work-based contexts: situation-based learning and activity-based learning. They indicate that in situation-based learning relevant activities and resources are recommended to the user, whereas in activitybased learning the user searches and selects proper activities and related resources. The authors emphasize that mobile learning systems provide feasible and helpful opportunities if learners want to switch from one strategy to another.

The second section of the book deals with exemplifying practices of mobile learning. This section includes six chapters that provide interesting but informative examples of mobile learning in a number of contexts such as education, medicine, and tourism.

Chapter 6, as the first chapter in this section, presents three m-learning case studies with the so-called Net Generation. All the three cases are related to school education. The first case is about a school district in Northern Canada that uses one-to-one computing in secondary education. The second case is about an autoethnographic approach in using m-learning for 
post-secondary education. The third case is about a school district in the United States that plans to implement m-learning across three schools to address the needs of the Net Generation. The chapter provides a summary of the findings across all the three case studies.

Chapter 7 reports on an in-depth, one year empirical research examining undergraduate students' uses of mobile devices. The study employed multiple research methods such as student e-journals, focus group discussions, student artifacts (visual images) observations, interviews, field notes, and memos. It was found that seven interacting factors could either facilitate or inhibit mobile device use. These are: learning goals, tasks to be performed, learning resources, mobile device capabilities/constraints, time and place, social factors such as institutional and physical conditions, and individual interpretations of the usefulness. The chapter ends with discussions on future research directions.

Chapter 8 describes the use of m-learning in the field of medicine. The author explains the medical context in general and specific characteristics of medical students, residents, and professionals in relation to implications for m-learning. The author asserts that the medical environment in which learning occurs necessitates m-learning due to a high degree of mobility, working in distributed sites, instant communications, and ongoing professional development.

Chapter 9 describes how the Open University of Malaysia has developed a mobile learning environment using SMS to enhance its current blended learning model. The chapter also addresses the categories used for formulating the SMS content, the use of Twitter and Facebook to support the SMS sent, the feedback received on the initiative, and challenging issues and problems. The authors contend that with over 98 percent of its students having mobile phones and 82 percent of the students ready for learning through mobile phones, Open University of Malaysia initiated a project first with podcasts and later SMS texts. The chapter summarizes how this project has evolved in the process and what outcomes have been achieved so far.

Chapter 10 reports a study investigating the use of podcasting as a means of facilitating and sharing learner generated content in hospitality management at the postgraduate level. The authors describe how the students generated content as learning objects using podcasts as the main medium to share information among themselves. The authors first review podcasting technologies' influence in education, then analyze and discuss the use of learner generated content in hospitality as well as the wider context of tourism and leisure subjects.

Chapter 11 discusses the use of mobile technologies in the second language classroom. Considering some of the long-lasting difficulties in vocabulary acquisition, the authors describe an attempt to resolve the problems through the use of mobile devices as digital flashcards. Based on the results obtained from a small-scale study, the authors make recommendations about their pedagogical approach and the technology used. They also aim at creating a pedagogically sound and widely usable application of mobile devices in foreign language learning.

The third section of the book discusses the possibilities of extending mobile learning in various settings. This section covers four chapters that illustrate how mobile learning can be applied in innovative ways to develop solutions to challenging educational problems.

Chapter 12 expands the potential of augmented reality and mobile technologies. The author first compares virtual reality with augmented reality by distinguishing that virtual reality 
replaces the perception of people's immediate environment with artificial one but augmented reality enhances of the perception of immediate environment. As the author succinctly indicates, augmented reality is a blend of real and virtual realities. The author later elaborates on how mobile technologies offer a wide array of opportunities to incorporate augmented reality in education.

Chapter 13 reports a study on student perceptions and uses of wireless handheld devices in an Australian university. Using factor analysis and regression analysis to explain the findings of the survey the authors conclude that attitudes and behaviors directly contribute to perceived performance of such devices in the chosen context. Based on the implications of the results, the authors elaborate on alignment across various interfaces related to blended and mobile learning environments.

Chapter 14 discusses students' uses of mobile technologies in the field of speech pathology. The authors explain the appropriation of students' own mobile devices to support the development of clinical competency for speech pathology in a standardized patient clinic. The chapter describes a project that focused on the role of mobile technologies in supporting learning across different contexts. The authors report that the use of mobile technologies in a clinical practice setting can make a positive contribution to clinical competency development of students.

Chapter 15 presents another case study involving the possible use of library classification and subject headings as an element of contextual identification through mobile learning. The author contends that although this task creates a challenge to develop a materials evaluation process using library classification that is both user-friendly and technologically-savvy, mobile learning devices offer effective and efficient solutions. The chapter concludes with discussions of implications for today and tomorrow.

\section{Conclusion}

This book takes an interdisciplinary approach to the issues related to the use of mobile technologies in education in order to extend learning opportunities for varying audiences. It expands the theoretical foundations of mobile learning, presents sound applications in different areas, and discusses the implications for future. As a whole, it enlightens the reader about the great potential of mobile technologies for effective, appealing, and efficient learning for all individuals around the world. After reading the chapters carefully, one can easily reach the conclusion that mobile learning, as it represents one of the fastest growing areas of contemporary educational technology, holds an impressive track record of innovation both in technology and pedagogy.

Mobile learning addresses the needs of the Net Generation who demand or attend learning opportunities anywhere and anytime. Mobile technologies present robust alternatives toward this goal. However, the pedagogy of m-learning, although it has made great progresses, is not sufficient enough to fulfill the demands. This book provides a global perspective on mobile learning and augments that perspective with sample applications from different countries, written by leading experts. Compared with the previous academic work in this area, this feature makes this book unique of its kind. The book highlights the point that many countries embrace m-learning steadily and successfully. 
The book is written mainly for academics and practitioners in the field of distance education, although the entire audience is not limited with them. The book can also be used as a textbook for graduate students who are interested in the latest trends and developments in mobile learning. Finally, the book can be useful as a library reference book for educators as well as administrators of both formal and non-formal learning organizations. In this regard, the book accommodates important needs of multiple audiences so that it makes a great contribution to the educational technology literature.

Correspondence: Ali Simsek, Director, Institute for Communication Sciences, Anadolu University, Yunus Emre Campus, Eskisehir, Turkey 